\title{
A IMPORTÂNCIA DA ORIENTAÇÃO PROFISSIONAL E A CONTRIBUIÇÃO DO PROGRAMA JOVEM APRENDIZ PARA OS ADOLESCENTES
}

\author{
Isabella Karen Borges dos Santos ${ }^{\mathrm{i}} \oplus 0000-0003-0287-3481$ \\ Centro Universitário Cidade Verde - UniFCV \\ Michelle Aparecida Ferreira dos Santos ${ }^{\mathrm{ii}} \oplus 0000-0003-3647-9837$ \\ Centro Universitário Cidade Verde - UniFCV
}

RESUMO: O presente trabalho busca tratar a importância da orientação profissional na adolescência e discutir sobre programas de aprendizagem neste estágio. A relevância da seguinte pesquisa se dá ao fato de que é durante esse período que o adolescente está em constante desenvolvimento, onde está estruturando sua identidade, formando conceitos e autonomia e ter mediações neste estágio torna-se ainda mais fundamental neste processo. Destacar sobre a importância das mediações como maneira de facilitar o processo de apropriação de possibilidades como modo de facilitar este jovem em decisões tão pertinentes. O papel deste profissional e/ou instituição será importante para contextualizar, pontuar e ajudálo a definir quais escolhas são cabíveis e acolher as suas inseguranças, dúvidas sobre o futuro. Para compreendermos os desafios enfrentados por esses jovens precisamos entender quais são as características a ele atribuída pela sociedade e pelo próprio universo empregatício e em seguida tratar do assunto em questão. $\mathrm{O}$ seguinte artigo construiu-se a partir de uma revisão bibliográfica envolvendo materiais que de algum modo permeiam os assuntos envolvidos sob a luz da perspectiva histórico-cultural. Primeiramente apresentaremos o estágio do desenvolvimento humano da adolescência, sua construção história e conceito contemporâneo, seguida pelos programas de aprendizagem e de orientação profissional, e por fim fazer as correlações discutidas destacando a importância da orientação profissional nessa fase do desenvolvimento humano.

PALAVRAS-CHAVE: Adolescência. Orientação profissional. Aprendizagem.

\section{THE IMPORTANCE OF PROFESSIONAL GUIDANCE AND THE CONTRIBUTION OF THE YOUNG LEARNING PROGRAM TO ADOLESCENTS}

\begin{abstract}
This paper seeks to address the importance of vocational guidance in adolescence and to discuss learning programs at this stage. The relevance of the following research is due to the fact that it is during this period that the adolescent is in constant development, where he is structuring his identity, forming concepts and autonomy and having mediations at this stage becomes even more fundamental in this process. Highlight on the importance of mediations as a way to facilitate the process of appropriating possibilities as a way to facilitate this young man in such pertinent decisions. The role of this professional and / or institution will be important to contextualize, score and help you define which choices are appropriate and welcome your insecurities,
\end{abstract}

doubts about the future. In order to understand the challenges faced by these young people, we need to understand what are the characteristics attributed to them by society and by the employment universe itself and then address the issue in question. The following article was built from a bibliographic review involving materials that somehow permeate the issues involved in the light of the historical-cultural perspective. Firstly, we will present the human development stage of adolescence, its construction history and contemporary concept, followed by the learning and professional guidance programs, and finally make the correlations discussed highlighting the importance of professional guidance in this phase of human development.

PALAVRAS-CHAVE: Adolescence. Professional orientation. Learning. 


\section{Introdução}

O presente trabalho busca tratar a importância da orientação profissional na adolescência conduzida pelo profissional de psicologia, além de avaliar as contribuições e complicações existentes nos sistemas de aprendizagem. A relevância da seguinte pesquisa se dá ao fato de que é durante esse período que o adolescente está em constante desenvolvimento, onde está estruturando sua identidade, formando conceitos e autonomia.

A escolha profissional se torna um ponto muito marcante na vida do jovem visto que, a escolha de uma profissão ou até mesmo de um emprego temporário se torna um verdadeiro divisor de águas para se conquistar a tão preterida independência, e é justamente essa fase do desenvolvimento que é acompanhada por grandes transformações.

Para tanto, surge a necessidade de se ter um mediador, alguém que possa facilitar o processo de apropriação de possibilidades. Nesse caso um orientador profissional ou uma instituição voltada a capacitação desse jovem de modo que possa auxiliá-lo. Esta pessoa terá um importante papel na vida deste jovem, informando, direcionado, facilitando suas escolhas e acolhendo as inseguranças do futuro. Mas, para compreendermos os desafios enfrentados por esses jovens, precisamos entender quais são as características a eles atribuída pela sociedade e pelo próprio universo empregatício.

O presente trabalho busca então percorrer por estas discussões tratando primeiramente sobre o estágio do desenvolvimento humano da adolescência, sua construção história e conceito contemporâneo, depois passando pelos programas de aprendizagem e de orientação profissional, e por fim fazer as correlações discutidas destacando a importância da orientação profissional nessa fase do desenvolvimento humano.

\section{Metodologia}

O seguinte artigo construiu-se a partir de uma revisão bibliográfica por meio de leituras de livros, artigos, revistas e demais materiais que de algum modo permeiam os assuntos envolvidos, que destacam a importância da perspectiva histórico-cultural, sobre a adolescência, programas de aprendizagem e orientação profissional como olhar crítico e que justificam o sentido desta mediação para o adolescente. 


\section{A adolescência: uma perspectiva da Psicologia Histórico-cultural}

Ao falar de escolha de um jovem é preciso primeiramente contextualizá-lo em seu estágio de desenvolvimento: a adolescência. É importante reconhecer a imagem que é vendida desse jovem, pois isso muito explica a relação que a sociedade tem com ele pelo conceito contemporâneo estabelecido sobre a adolescência e o valor que lhe é atribuído.

Esta fase do desenvolvimento humano, assim como as demais, é marcada por diversos contextos, de modo particular é preciso reconhecer a adolescência enquanto fator histórico e cultural.

Dessa forma, consideramos que a adolescência é criada historicamente pelo homem, enquanto representação e enquanto fato social e psicológico. É constituída como significado na cultura, na linguagem que permeia as relações sociais. Fatos sociais surgem nas relações e os homens atribuem significados a esses fatos. Definem, criam conceitos que representam esses fatos. São marcas corporais, são necessidades que surgem, são novas formas de vida decorrentes de condições econômicas, são condições fisiológicas, são descobertas científicas, são instrumentos que trazem novas habilidades e capacidades para o homem. Quando definimos a adolescência como isto ou aquilo, estamos constituindo significações (interpretando a realidade), a partir de realidades sociais e de marcas que serão referências para a constituição dos sujeitos (OZELLA, 2002, p. 16).

O que se vê a partir dessa citação é que este fenômeno foi sendo conceituado ao longo do desenvolvimento histórico e mesmo assim seus conceitos tanto no passado quanto atualmente não garantem a universalidade desse fenômeno, pois é através das formas pelas quais o homem interage com a sociedade e é moldado por ela que surgem novos contornos e sentidos para esse conceito que muda conforme a cultura e o tempo histórico e continua em constante mudança toda vez que este mesmo processo ocorre. Cabe atrelar a este fato que a cultura, a linguagem, e as representações sociais, questões socioeconômicas dentre outros fatores, que significam esse estágio do desenvolvimento humano vão atuar segundo os costumes e compreensões que seguem a historicidade desse meio. E é possível notar essas distinções até mesmo em bairros próximos com padrões de vida diferentes que consequentemente têm costumes, cultura e linguagem diferente para descrever o fenômeno da adolescência.

Segundo Ozella (2002) a adolescência estaria ligada a estereótipos e estigmas, onde se encontram uma fase marcada por tormentos e conturbações vinculadas à sua sexualidade. Conforme Mascagna e Facci (2014): 
Refletir acerca da adolescência implica, inicialmente, problematizar o conceito em questão. A adolescência é uma fase conhecida tanto no campo científico como no senso comum, como uma idade turbulenta, conflituosa, caracterizada pela rebeldia e cheia de hormônios. Predomina, muitas vezes, uma visão biológica para essa fase de desenvolvimento, uma naturalização de comportamento que, no nosso ponto de vista, são constituídos em uma sociedade dada, situada historicamente. (MASCAGNA; FACCI, 2014, p. 45).

Então o primeiro passo é considerar este adolescente inserido em um contexto composto por múltiplas determinações. Ozella (2002) reforça o conceito incluindo as definições psicanalíticas que contemplam uma caracterização da fase onde se tem confusões, estresse e luto. "No desenvolvimento dos interesses, ocorrem duas etapas principais: os novos interesses e o desenvolvimento do sistema novo que se forma sobre os novos interesses." (MASCAGNA; FACCI, 2014, p. 54). Surgem novas cobranças e outras coisas passam a atraí-lo dando uma nova forma de viver a vida.

O jovem entra em crise porque, apesar de romper com os vínculos que tinha antes, ou seja, família e escola, e de querer adentrar nas novas relações sociais, ele ainda não adentrou por completo nessas relações. Ainda permanece na escola e suas aspirações não podem ser realizadas, então o jovem vive uma vida imaginativa. A atividade dominante dos adolescentes não se reduz apenas ao estudo, nela de acordo com Elkonin (1987), também ocorre a comunicação pessoal entre os adolescentes (MASCAGNA; FACCI, 2014, p. 54).

Segundo Santos, Neto e Souza (2011) os adolescentes são comumente vistos como sujeito-problema onde normalmente são relacionados a rebeldia, sexo, bebidas e drogas ilícitas, além de serem definidos como irresponsáveis e imaturos para tomarem decisões. Os autores apontam a mídia como um fator que costuma reproduzir esse discurso trazendo consigo uma ideia universalizante da adolescência, eles observaram que os conceitos trazidos pela mídia muito têm a ver com a visão social e da própria instituição familiar sobre este jovem, onde se é visto como naturalidade da fase a rebeldia e que seria supostamente irremediável de se mudar a vivência da mesma.

E nesse mesmo ponto se encontra uma certa incoerência dos veículos midiáticos porque eles devolvem aos pais o adolescente problema alegando que sua rebeldia é advinda de uma incompetência dos mesmos por não terem autoridade sobre os filhos desse modo se lança a seguinte questão: Se a rebeldia e demais características são naturais da adolescência e são questões imutáveis como podem os pais ter responsabilidade pelo comportamento de seus filhos? E como podemos depositar qualquer responsabilidade se esse adolescente é incapaz de se responsabilizar ou ter opiniões e ideias maduras? 
Santos, Neto e Souza (2011) apresentam que a mídia materializa o que a maioria das pessoas pensam sobre a adolescência. Dessa imagem estereotipada, conclui-se que o jovem é um indivíduo sem autonomia, incapaz de fazer escolhas importantes ou de se proteger, quase considerado nesse período do desenvolvimento como um desserviço social. Tal estigma se intensifica para os adolescentes de periferia.

Para Ozella (2019) foram as concepções de rebeldia, estresse, impetuosidade, enfim, adolescência resumindo-se a um estágio conflituoso que passaram a reverberar na psicologia e a se introduzir na cultura ocidental, e por sua vez foi sendo entendida pelo homem. Desse modo, entende-se que a adolescência foi sendo construída através da história e das descobertas científicas. O autor traz o princípio de que as primeiras visões sobre a adolescência se caracterizavam como sendo uma fase naturalista e universal, que foi perdendo força devido às novas análises que foram feitas no decorrer do tempo ao passo em que foram sendo construídas novas formas de se pensar a adolescência até o tempo ao qual estamos hoje.

Para Ozella (2002) a adolescência deve ser vista para além de um estado, mas como condição social, ele faz uma crítica aos argumentos pautados na psicologia tradicional onde condiciona-se a adolescência como um fenômeno que é preexistem, naturalista e universalizante. Nesse sentido, entende-se que por mais que a adolescência tenha fatores biológicos envolvidos, as mudanças e a organização de sua subjetividade e a forma com que lidará com estas transformações dependerá além das condições biológicas e ambientais enfrentadas, das possibilidades de seu meio e mediações neste processo. Desta forma, o caráter de suas escolhas e as próprias perspectivas que o sujeito tem de si e de seu contexto são construídas neste estágio.

Ozella (2002) considera que esse fenômeno deve ser configurado de forma que legitime a presença dos fatores culturais, da historicidade, dos contextos e das representações sociais que se fazem do mesmo e que propriamente nominam a adolescência .O autor põem em cheque a ideia de que as condições biológicas seriam os fatores propulsores para o desenvolvimento, perante seu olhar a psicologia tradicional estaria negligenciando e não admitindo esses fatores, ao suporem que há igualdade de oportunidades entre os adolescentes.

Coloca no jovem a responsabilidade pelas dificuldades que existem nas relações sociais, sem observar seu meio, avaliar seus recursos e possibilidade para se fazer uma escolha. Analisando este ponto observamos que o adolescente tem poder de escolha de acordo com sua realidade, porém, o autor enfatiza a necessidade da presença de 
instrumentos e/ou profissionais adequados que deem condições suficientes para que ele se desenvolva e possa fazer escolhas satisfatórias para que possa planejar o seu futuro de acordo com seus recursos. Dessa forma, é de suma importância que haja investimento em recursos, estudos e aplicação de métodos que venham ao encontro das necessidades desse sujeito para que ele adquira autonomia e esteja pareado com os demais em todas as fases desse processo do desenvolvimento.

É preciso destacar as principais características vivenciadas neste momento a fim de apresentar o porquê é tão conturbado o momento da escolha de uma carreira e como a orientação profissional e o jovem aprendiz têm contribuído para tornar este período um pouco menos intenso. Segundo Campos (2012) às várias transformações corporais a qual o adolescente está sujeito podem causar um choque psicológico, mas considera que no decorrer da adolescência o sujeito é vulnerável não só as mudanças biológicas, mas também das mudanças provocadas por sua nova posição social diante das pessoas o que pode lhe causar insegurança e estranheza dado a mudança ligeiramente abrupta que lhe ocorreu, pois seu corpo mudou e mais do que isso socialmente é exigido deste adolescente um novo papel e outro nível de maturidade psicológica.

Para Campos (2012) o mundo moderno atinge diretamente o adolescente com suas grandes mudanças não só em proporção mais em impacto direto mudando toda a dinâmica das relações. Um desses aspectos seriam para ela as explosões demográficas, progresso científico, a tecnologia, as comunicações, as novas aspirações humanas e a rápida transformação social. Tudo isso para ela torna o jovem vulnerável por não ser capaz de dirigir toda essa realidade que em sua infância lhe era omitido uma vez que não era necessário assumir papéis de responsabilidade tão ativos, relações sociais tão complexas além de uma figura mais autônoma e gestora de si marcada por decisões extremamente importantes.

Ao mesmo tempo em que traz inseguranças já que ainda não é completamente independente e precisa estar constantemente reafirmando a independência parcial que adquiriu. Nesse sentido a autora Campos (2012) afirma que os adultos tendem a ter atitudes ambivalentes quanto aos adolescentes e na maioria das vezes são atitudes negativas onde incorporam críticas severas aos mesmos. Ela salienta que seriam críticas não ao indivíduo em si mas uma generalização de críticas direcionadas a sua categoria, Campos (2012) denomina essa atitude como luta entre as gerações. Diante disso compreende-se que o adolescente se encontra em uma nova realidade onde sua estrutura corpórea lhe indica uma 
DOI 10.33872/revcontrad.vlnl.e004 | v. 1, n. 1| Jan./Jun. 2020

maturidade que sua estrutura psíquica ainda não conseguiu parear-se, portanto ocorrem diversos desafios a serem superados juntamente com uma ebulição de sentimentos.

O mesmo se encontra em um processo onde não é mais uma criança, porém tão pouco é um adulto, contudo lhe é exigido responsabilidade tal qual ao adulto ao mesmo tempo em que é desacreditado, estigmatizado ou altamente responsabilizado por uma questão de escolhas que tem de decidir. E é nesse emaranhado de contradições que o adolescente tem que se desenvolver, com todas as suas inseguranças, dificuldades, transformações, ideias, dúvidas, seus objetivos entre outras características conflitantes. E vale considerar que todos esses pontos levantados ainda recebem o peso das questões culturais, socioeconômicas, recursos pessoais para então compreender o que é o adolescer daquele indivíduo e como trabalhar com suas necessidades e conhecimentos dentro de seu contexto.

Ao traçar esse conceito trazido por Ozella (2002), conseguimos se inteirar das problemáticas e da necessidade de haver antecipação dos acontecimentos que dizem respeito ao desenvolvimento para que esse jovem esteja bem estruturado e tenha recursos de ação suficientes para se gerir, escolhendo assim sua profissão de maneira assertiva, traçando metas e reconhecendo seu meio e projetando maneiras para trabalhar nele, e por isso ele precisa de auxílio externo (como ambiente adequado).

Nessa lógica a escolha profissional têm sua importância por propiciar a possibilidade de um "terreno adequado" para que se germine bem e produza-se bons frutos, ou seja, um bom profissional não nasce da noite para o dia ele precisa ser preparado em outras palavras ter qualificação como bem destaca a necessidade de mercado atual. Preparamos o terreno e cuidamos da semente até se tornar autônoma. Sendo assim, marcada por exigências do próprio sistema capitalista vigente, esta fase não está isenta de suas contradições bem como de suas próprias características de: individualismo, competitividade, busca pelo prazer, etc. E esse é o momento em que surgiram muitas dúvidas para este adolescente dentre elas inseguranças, angústias, sensação de desamparo etc.

Segundo Almeida e Pinho (2008) há vários fatores que definem as escolhas profissionais e um dos principais seriam a constituição familiar, pois é na família que ele irá adquirir muitos conceitos como: princípios morais, religiosidade, os valores que eles darão a algumas áreas profissionalizantes que futuramente contribuirão para sua escolha entre outros. As escolhas profissionais para um adolescente envolvem mais que seus desejos e ambições, envolvem também saber quem são, como se enxergam e como se veem no mundo. Não se trata de habilidades apenas, é uma mudança de estilo de vida que depende 


\section{DOI 10.33872/revcontrad.vlnl.e004 | v. 1, n. 1| Jan./Jun. 2020}

das condições objetivas que lhe são apresentadas (condições socioeconômicas, escolarização, mediações etc.).

Segundo Almeida e Pinho (2008), o indivíduo desde o nascimento já é bombardeado de expectativas em que os próprios pais acabam depositando seus sonhos no futuro dos filhos. Além, dessas expectativas familiares, também existem as expectativas sociais, que sobrecarregam o peso das responsabilidades se tornando muito difícil estabelecer uma escolha que necessariamente envolve quem ele será para ele mesmo, gerando grande insegurança, pois uma possibilidade de escolha irá descartar todas as outras.

\section{A escolha profissional e os programas de aprendizagem}

Depois de traçarmos algumas breves discussões sobre a adolescência e a importância desta fase na construção de identidade e conceitos do sujeito passamos então a destacar sobre a escolha neste período. Almeida e Pinho (2008) declaram que a orientação profissional será importante para esclarecer de forma mais consistente os motivos de sua escolha e até mesmo das influências familiares que o levaram a ter essa tomada de decisão propiciando ao jovem mais clareza de seu futuro que ainda lhe parece incerto. "A perspectiva liberal joga nas mãos do indivíduo toda a responsabilidade pelo sucesso ou insucesso que pode alcançar." (BOCK, 2010, p.20). O autor ainda reforça na necessidade de construção de políticas públicas educacionais com intuito de tornar a Orientação Profissional uma condição educativa imprescindível à escolha profissional. Dessa forma, ele poderá se programar e fazer uma escolha mais assertiva e de modo mais crítico e consciente (BOCK, 2010, p.143).

É preciso ainda destacar que as tomadas de decisões são marcadas por determinantes sociais e econômicos, ou seja, pelas condições potencializadas pelo capitalismo e pelo Estado com o objetivo de apresentar os pontos sociais vulneráveis que colocam muitos jovens a margem da sociedade. Segundo Bock (2010):

A história da política educacional e da formação de mão de obra no Brasil também mostra a exclusão das classes pobres da temática da escolha profissional. Às pessoas empobrecidas da nação brasileira restava o destino do trabalho precoce, e quando uma qualificação profissional era cogitada, sempre aparecia como alternativa de segunda linha o aprendizado de habilidades para o desempenho de um ofício. (BOCK, 2010, p.19) 
Reconhecer que os fatores sociais são implicações importantes para a realização ou não de determinada escolha profissional, e que as trajetórias por vezes distintas interferem na identidade profissional isso se torna importante para assimilar como se desenrola este processo.

Para cada um desses públicos, o significado do trabalho e a importância se distinguem, contudo, as pressões são sentidas em ambos. Para trabalharmos essas questões é importante resgatarmos os conceitos de significado social e sentido pessoal, para que possamos compreender como se dá esta escolha profissional para o adolescente na atualidade.

Segundo Leontiev (2004) o significado social está ligado diretamente à construção histórica da humanidade, ou seja, tudo o que foi construído na relação entre os homens no decorrer da história assim como as práticas sociais desenvolvidas no percurso desse processo. Desta maneira, o indivíduo ao nascer já está imerso em um sistema de significações do qual ele se apropria ao longo de seu desenvolvimento, fazendo parte de seu processo de humanização.

Partindo desta reflexão, verificamos que o adolescente a medida em que está neste momento da escolha, vai encarar esta profissão de acordo com o arcabouço já construído historicamente pelos homens, o que está posto. Qual a imagem socialmente construída desta escolha? Já pelo conceito de sentido pessoal, Leontiev (2004) o descreve na relação entre o sujeito e objeto, em que no processo de apropriação dos significados sociais já elencados, atribui o sentido que lhe é particularmente influenciado por sua forma de sentir, agir e pensar, ou seja, neste processo de escolha cada sujeito faz de uma forma diferente conforme as individualidades de sua história de vida, condições materiais, e formação subjetiva a partir das mediações objetivas estabelecidas. A orientação profissional de fato é vivida pelos jovens independente de classe social? "Na prática, efetivar uma escolha profissional pode ser um momento complexo para o jovem, pois ele não estará definindo somente uma profissão, mas um sentido e um projeto de vida" (BORGES, 2017, p.211).

Compreende-se então que este trabalho descreve não só um ofício, mas quem ele é ou quer tornar-se, está ligado a suas afinidades, sonhos, projetos, planos e habilidades e acima de tudo informação. Esse trabalho é uma expressão de si mesmo é uma marca do que ele representa socialmente em seu trabalho e do valor significativo que ele possui em seu meio gerando valorização de si mesmo pelo reconhecimento recebido diante do trabalho realizado. Dessa forma, quando existe empobrecimento dos recursos e qualificações desses sujeitos, como por exemplo nas instituições de ensino a capacidade desse sujeito fica mais 
limitada tornando seu processo mais conflituoso, desgastante, sem muitos caminhos para chegar ao seu objetivo etc. Então partindo desse ponto é potencializada a possibilidade de fragmentação de seus projetos de vida dado aos grandes obstáculos existentes frente ao seu pequeno arcabouço e despreparo para lidar com os mesmos. "Assim, também entendo que o processo de escolha profissional não é uma ação linear, mas vai compondo-se por meio das relações objetivo-subjetivas, diariamente" (BORGES, 2017, p.212).

Assim sendo cada escolha profissional vem marcada por um processo de escolhas subjetivas e objetivas que irão ser determinantes para a escolha final deste adolescente. E é nesse ponto que devemos compreender que tanto as influências subjetivas quanto as objetivas devem corresponder a um quadro saudável que só pode ser adquirido se o meio for favorável e o mesmo tiver suas capacidades cognitivas exploradas da melhor forma.

Faria e Guzzo (2007) realizaram uma pesquisa com 20 estudantes, de onde esses 10 eram de escola pública e os outros 10 de escola particular. Eles tinham o intuito de analisar a visão desses jovens para os seguintes conceitos: emprego, trabalho e profissão. Faria e Guzzo (2007) observaram que tanto os alunos de escola privada quantos os alunos de escola pública compreendem o trabalho como base para os outros dois conceitos (emprego e profissão). Contudo é visto que os alunos de escola pública não enfatizam esforços individuais para ter ascensão profissional de maneira tão acentuada como os alunos de escola privada, os alunos que compõem os dois grupos entendem a profissão como um trabalho que foi escolhido podendo virar uma carreira. Porém os alunos de rede pública avaliam que um emprego pode virar um trabalho e por consequência uma carreira.

Os autores descrevem que os alunos de rede pública atrelam o sucesso a uma condição melhor de vida, a padrões mais justos o que difere dos alunos de instituição privada que atrelam o sucesso a uma carreira profissional que desfrute de riquezas, e status social etc., ambos os grupos veem a profissão com a ideia de "dom" "vocação" "talento", mas os alunos de escola privada valorizam mais estes fatores. A partir da análise dos autores, pode se identificar, o quanto podem ser diferentes os valores que os grupos de adolescentes empregaram ao trabalho e a escolha de uma profissão, ou seja, as condições materiais que influenciam os sentidos pessoais das escolhas profissionais.

As condições sociais interferiram de maneira significativa para que obtivessem essa visão, os alunos de escola pública veem o trabalho como algo que os escolhe quase que como um destino, e os alunos de ensino privado conseguem ver os esforços pessoais e a 
escolha para se realizar o que dá a noção da grande discrepância social a qual os jovens não abastados devem enfrentar além das transformações já contidas na adolescência.

Com todas as dificuldades já citadas existem ainda outras a serem enfrentadas como a falta de oportunidade de emprego e por sua vez as qualificações necessárias para um ingresso efetivo no mercado. Para tanto, foram criados programas como o jovem aprendiz que são responsáveis por capacitar os jovens e ingressá-los no mercado de trabalho.

Calazans, Souza e Ficher (2014) apontam que a Lei que regulamenta a Aprendizagem $n^{\circ} 10.097 / 2000$ e pelo Decreto $n^{\circ} 5.598 / 2005$, também é a mesma que dá possibilidade para que estes programas existam. Os autores afirmam em sua pesquisa, que os setores empregatícios têm exigido experiência e esse seria um dos fatores que tem dificultado a entrada dos jovens no mercado de trabalho, em que os mesmos acabam cedendo ao mercado informal e ficam marginalizados. Tal exigência torna ainda mais difícil a participação do jovem no mercado de trabalho, podendo acarretar em baixa autoestima, desmotivação, dificuldade em traçar projetos de futuro etc. Desse modo, programas como o jovem aprendiz se tornam uma válvula de escape para muitos jovens que se encontram como os próprios autores mencionam "marginalizados” ou excluídos.

Os autores Calazans, Souza e Ficher (2014) também se referem aos programas de jovem aprendiz como sendo responsáveis não só por garantir a primeira experiência profissional com possível contratação, mas também caracterizá-la como capaz de qualificálos como profissionais sem atrapalhar seu rendimento escolar e comprometer seu desenvolvimento como pessoa.

Entre os anos de 2006 e 2010 contavam com 51.965 para 100.474 aprendizes o que significa dizer que este programa pode causar uma ruptura significativa dos problemas que estavam sendo vistos nos anos passados, especificamente nos anos 80 e 90. Calazans, Souza e Ficher (2014) relatam que em um primeiro momento o programa de aprendizagem não tinha a intenção de ter um caráter profissionalizante e de inserção dos jovens para o trabalho, mas servia apenas para "proteger" jovens de regiões menos favorecidos no Brasil. Ao analisar essas informações podemos verificar que não havia espaço, intenções de inclusão desses jovens. Essas brechas eram dadas a jovens menos favorecidos com o suposto objetivo de protegê-los e garantir seu futuro.

Contudo, havia ausência de desenvolvimento profissional que viessem garantir ascensão profissional. Eles eram treinados através do método mecanicista para serem "mão de obra barata" nas indústrias da época, onde não existiam número substancial de profissionais que soubessem trabalhar nas máquinas. Esse feito corroborou para a 
perpetuação de um ciclo de desigualdade: se de um lado jovens de regiões abastadas estudavam e tinham um leque vasto de possibilidades para escolher suas profissões e desfrutar de sua adolescência, do outro, haviam jovens sendo escolhidos pelo mercado de trabalho devido sua situação vulnerável e impossibilidade de escolha se sujeitava a isto e as indústrias se aproveitavam dessas condições para submetê-los a este ciclo vicioso. Com o tempo, houve uma evolução na metodologia do jovem aprendiz que hoje conta com o desenvolvimento de competências técnicas em âmbitos mais ampliados que não tange somente ao sistema industrial, além disso, o jovem aprendiz visa articular a competência técnica com as competências pessoais e acadêmicas do sujeito. Com isso, os jovens obtiveram um espaço maior no mercado de trabalho abrindo possibilidades que antes eram muito mais difíceis.

Contudo, essa abrangência ainda não é substancial a ponto de garantir a não marginalização, pois ainda há alguns obstáculos como as exigências do mercado e as negligências do Estado para preparar o indivíduo neste contexto. De modo geral, o jovem aprendiz busca garantir a experiência profissional que era de difícil acesso anteriormente porque o mercado se mantinha com as portas fechadas para esse público e atualmente passou a ser legal e essencial a presença desse método.

Calazans, Souza e Ficher (2014) ao final da pesquisa verificaram que os alunos atribuem a ser um jovem aprendiz características como: sempre estar disponível, disposto a aprender e aceitar mudanças mesmo com os medos e inseguranças que a adolescência possa trazer. Os mesmos identificaram os benefícios do programa como o de que estariam obtendo uma experiência profissional, trabalhando em equipe, adquirindo responsabilidade, maturidade, visão de mercado, respeito às regras e principalmente as pessoas, além disso, os aprendizes apresentaram que na maioria dos casos conseguem usar parcialmente o que aprenderam ao decorrer do curso.

A partir disso, Calazans, Souza e Ficher (2014) fizeram um gráfico onde continham os pontos de maior importância pela procura desses jovens ao programa jovem aprendiz e os pontos que mais foram destacados, foi o interesse dos mesmos por serem reconhecidos por aqueles que os rodeiam. Os autores entendem esse aspecto como algo difícil de nominar por sua abrangência, e por isso, atribuíram esse sentimento como "crescimento pessoal", outros como visão de mundo, ou seja, enxergar a realidade e a prática das organizações, a inserção no mercado de trabalho, novos conhecimentos e independência financeira.

Os dados levantados apresentaram que o trabalho para estes jovens possuem maior valor e significado pessoal do que propriamente financeiro, por mais que o trabalho tenha 
funções objetivas como o próprio sustento para eles o trabalho terá valor imaterial, que englobam: sentimento de utilidade, competência, engajamento, dignidade, maturidade etc. Não havendo este espaço de desenvolvimento social acredita-se então que todos esses valores são prejudicados, podendo desenvolver um profissional desacreditado de si mesmo ou marginalizado assim como os autores apontaram em sua pesquisa.

No que diz respeito a contribuição da orientação profissional Oliveira e Pessoa (2005) definem sua importância como promoção de auxílio para que os adolescentes possam tomar uma decisão adequada. A escolha profissional depende do indivíduo que por sua vez, é marcado por determinantes socioeconômicos, mas que de qualquer modo não pode ser delegada. Sendo assim, o jovem precisa de um espaço e condições para elaborar seus conflitos e ansiedades para que possa definir seu projeto de vida.

Os autores Oliveira e Pessoa (2005) destacam que para os jovens o futuro é empregado como um papel a ser assumido dentro da sociedade e que na nossa cultura são as características que estabelecem como uma profissão deve ser definida como sendo capaz de determinar o valor social do sujeito.

Segundo Oliveira e Pessoa (2005) é na adolescência que o sujeito desenvolve identidade ocupacional. Para adquiri-la é necessário que os mesmos elaborem seus conflitos, identifiquem suas satisfações profissionais, integrem suas diferentes identificações e saibam o que desejam fazer. Os autores defendem que será o psicólogo o responsável por promover essas identificações, dando a eles condições adequadas para: pensarem a respeito, ter autoconhecimento, exercício do mesmo e consciência das identificações e condições sociais que proporcionaram essa escolha. Ao analisarmos essa afirmação é notório o divisor de águas que o psicólogo passa a ter na vida desse adolescente, e seguindo mais adiante esse psicólogo tem um grande valor social e suas competências devem ser valorizadas porque ele consegue trazer um melhor desempenho pessoal e profissional a nível de mercado, profissionais satisfeitos geram investimentos pessoais, e sociais inimagináveis. É necessário que o trabalho do mesmo seja visto com cuidado, respeito e reconhecimento. É preciso reconhecer o compromisso social dos orientadores profissionais com os seus orientandos:

[...] parte-se da premissa de que há um compromisso social dos orientadores profissionais com seu público, entendendo a OP como uma prática estimuladora, pois o jovem deverá pensar na construção do seu futuro e (re)pensar o significado e os valores do trabalho, dando-se conta da sua situação presente e traçando planos coerentes com sua realidade socioeconômica e cultural, suas expectativas/oportunidades vindouras, de modo crítico e consciencioso (BORGES, 2017, p. 212-213). 
DOI 10.33872/revcontrad.vlnl.e004 | v. 1, n. 1| Jan./Jun. 2020

Desta forma, amparar este jovem no momento da escolha é fundamental, visto que este também está em processo de construção de sua própria identidade e que seu contexto também está determinado por múltiplas condições históricas, sociais e econômicas.

\section{Considerações Finais}

A orientação profissional e os programas governamentais como o jovem aprendiz devem ser vistos como prioridade no auxílio de adolescentes nas novas empreitadas que terão de enfrentar. É preciso ter em vista que necessitamos de mais do que profissionais competentes em seus ofícios, profissionais conscientes de suas escolhas, críticos, e dentro das possibilidades realizados em suas vidas, pois uma boa escolha profissional promove saúde, qualidade de vida e trabalho, diminuem o número de pessoas desempregadas, além de evitar adoecimentos.

O adolescente possui papel ativo sobre todo o processo de desenvolvimento cabendo ao psicólogo torná-lo consciente desse papel. Quando o adolescente se torna consciente de sua figura ativa perante suas escolhas, passa a refletir sobre as tomadas de decisão e as consequências que elas dão, essas informações são captadas através do papel auxiliador do psicólogo.

Observadas as informações atribuídas até aqui identificamos a necessidade do jovem de se sentir valorizado e útil, o que justifica seu desejo e conceituações sobre estas profissões. Para que esta escolha possa ser mais assertiva, a presença de uma figura norteadora como a do psicólogo na orientação profissional ou um educador, é fundamental. Uma pessoa que o auxilie e evite que este jovem possa vir a se forçar a ocupar determinado espaço para ser aceito e não para obter satisfação profissional.

Esse fator é um implicador para que os mesmos passem a pensar que suas profissões podem objetificá-los tornando-os competentes ou não mediante aos padrões sociais.

Sugere-se que este trabalho envolve metodologias diversas, desde diálogos, dinâmicas, tarefas de reflexões, enfim que possam abordar assuntos como: conceito de trabalho; história da luta de classes; autoconhecimento; significado social do trabalho e sentido pessoal; profissões existentes; formas de acesso ao ensino superior; cultura das profissões universitárias; metodologias de expressão para objetivar pensamentos e organizar ideias; enfim, temáticas que podem enriquecer e dar mais ferramentas internas para uma escolha melhor direcionada, sendo essencial o papel de um psicólogo neste processo. 
DOI 10.33872/revcontrad.vlnl.e004 | v. 1, n. 1| Jan./Jun. 2020

Diante das reflexões postas, encaramos que se faz urgente e necessário um maior investimento em políticas públicas educacionais voltadas à Orientação profissional garantindo o acesso de todos nestas reflexões.

\section{REFERÊNCIAS:}

ALMEIDA, M. E. G. G. de; PINHO, L. V. de. Adolescência, família e escolhas: implicações na orientação profissional. Psicologia Clínica [online]. 2008, vol. 20, n. 2, pp. 173-184. https://doi.org/10.1590/S0103-56652008000200013

BOCK, S. D. Orientação profissional para as classes pobres. São Paulo: Cortez, 2010.

BORGES, R. C. Juventudes: sentidos do trabalho e o processo de escolha profissional. In: LISBOA, M. D.; SOARES, D. H. Orientação Profissional em Ação: formação e prática de orientadores. São Paulo: Summus, 2017.

CAMPOS, S. Psicologia da adolescência: normalidade e psicopatologia. $24^{\circ}$ Ed. Petrópolis, RJ: Vozes, 2012.

CALAZANS, S. J. P.; ZAMONER, e FICHER. Programa de aprendizagem profissional e sua contribuição mercadológica: Uma análise sobre a perspectiva aprendiz, professor e empresa. Bioenergia em Revista: Diálogos, ano 3, n. 1 p.35-38, jan./jun./2014.

CONTINI, M. de L. J.; KOLLER, S. H. (Orgs.). Adolescência e psicologia: concepções, práticas e reflexões críticas. Rio de Janeiro: Conselho Federal de Psicologia, 2002.

FARIA \& GUZZO. Em tempo de Globalização: A representação social de emprego, trabalho e profissão em adolescentes. UERJ. N. 3, 2 sem., Rio de Janeiro, 2007.

LEAL, Z. F. R. G; FACCI, M. G. D.; SOUZA, M. P. R. de S. (Orgs.). Adolescência em foco: contribuições para a psicologia e para a educação. Maringá: EDUEM, 2014.

LEONTIEV, A. O desenvolvimento do psiquismo. Tradutor Rubens Eduardo Frias. $2^{\mathrm{a}}$ Ed. São Paulo: Centauro, 2004.

OLIVEIRA, Q. N.; PESSOA, C. R. A importância da orientação profissional para o direcionamento de carreira na adolescência. Revista Psicologia.pt. UNIJORGE, 2013. Disponível em: https://www.psicologia.pt/artigos/textos/TL0343.pdf Acesso em: 24 jul. 2020.

OZELLA, S. Adolescência: uma perspectiva crítica. In: Adolescência e psicologia: concepções, práticas e reflexões críticas. Rio de Janeiro: Conselho Federal de Psicologia, 2002.

PRAÇA, F. S. G. Metodologia da pesquisa científica: organização estrutural e os desafios para redigir o trabalho de Conclusão. Revista Eletrônica Diálogos Acadêmicos, 2015, p. 7287. Disponível em: <http://uniesp.edu.br/sites/_biblioteca/revistas/20170627112856.pdf> Acesso em: 13 jun. 2019.

SANTOS, M.; NETO, M. \& SOUZA, Y. Adolescência em revistas: um estudo sobre as representações sociais. UFP, Psicologia: Teoria e Prática, 2011.

\footnotetext{
i Acadêmica do curso de graduação em Psicologia (UniFCV). Email: isabella.borges576@ gmail.com
} 
ii Mestre em Psicologia (UEM), professora e coordenadora do curso de graduação em Psicologia (UniFCV). Email: michellesantos1987@ hotmail.com 